\title{
Quality of Worklife Human Well-being Linkage: Integrated Conceptual Framework
}

\author{
Mohi-Adden Yahya Al-Qutop \\ Faculty of Economics and Adm. Sciences \\ Business Administration Department, Applied Science Private University \\ Amman, Jordan \\ Tel. 962-795-573-233 E-mail: alqutop @ hotmail.Com \\ Professor Hussein Harrim \\ Faculty of Economics and Adm. Sciences \\ Business Administration Department, Applied Science Private University \\ Amman, Jordan \\ Tel.962-6582-2783 E-mail: h_harrim @ hotmail.com
}

Received: February 22, 2011 Accepted: March 17, 2011 doi:10.5539/ijbm.v6n8p193

\begin{abstract}
Quality of work life (QWL) is not only one of the most important domains in peoples' lives, but also affects and shapes many of the components of the general/ total quality of life (wellness) of organizational members, as well as other peoples at the community, national, regional and even global levels.

There has been ample research studying QWL, but very little attempts have been made to link QWL with general wellness/ well - being. As peoples every where suffer from the many unfortunate and sad crises and outcomes brought by organizations, QWL deserves more intensive and in-depth research, especially examining QWL linkage with whole well - being. This paper attempts to provide a framework of guidelines to help organizations create and develop high QWL that can enhance and promote the welfare, goodness and total wellness, not only of organizational members, but also all other stakeholders and the broader societies at community, national and global levels. Thus, developing and nurturing among organizational members not only good organizational citizenship behavior, but also good national and even global citizenship behavior.
\end{abstract}

Keywords: Human resource management, Quality of worklife, Human well-being, Conceptual model

\section{Introduction}

It is safe to describe our age as an age of organizations. Organizations of various types and sizes have become a dominant type of institution everywhere. They control the national wealth and resources, and deeply penetrate, influence and shape the various spheres and domains of our lives (economic, political, social, cultural, educational, health, recreational, etc.). Yes, organizations have brought and provided many blessings to human kind. But, they have brought so many unblessings and negative outcomes, crises, and catastrophic disasters to mankind and earth planet such as global warming, pollution, environmental and ecological destruction, threats to mankind, animals, and plants, exhaustion of natural resources, famine, stresses, poverty, exploitation, suppression, etc. As organizations and business have become boundary less, so organizational outcomes cross borders to reach other nations and continents. Organizational members contact, communicate and interact with clients, suppliers, government representatives and others from other countries.

Various elements and domains of our lives are tied to the actions of organizations. Most people everywhere spend many hours a week and many years of their walking lives at work or job activities. Indeed most adults organize their lives around work. Work plays a major role in the adult's sense of self. When meeting a person, one of the first questions that come to mind is "what do you do for a living?" To a large extent, an individual defines himself/ herself and others in terms of his/ her work.

\section{Organizational Challenges and Problems}

Today's organization's witness, and will witness in the future, serious challenges, transformations, changes, pressures and demands from various sources. A great challenge facing mangers is a very dynamic and ever-changing environment. Ultimately, say (Schermerhorn etal. 1994,56) this environment is creating pressures for the emergence of a new workplace whose systems, structures, and practices are consistent with the emerging social values and expectations" They add, managers must address significant issues such as: total quality 
management, global economy, workforce diversity and shifting population demographics, concerns for human rights in the workplace, organizational transitions, developments in information technologies, and new ways of organizing. Other significant common issues and problems that managers need to address include: employees feel isolated, disconnected, lack meaning in life, the nature of work is changing as a result of increasing globalization and a shift from the industrial age to the information age and knowledge society and economy, which has resulted in longer work hours, and increased expectations for productivity, accompanied by less job security, a lower organizational loyalty, due to downsizing, layoffs and increased work-life conflict (Kinjerski and Skrypnek, 2006).

Robbins and Coulter $(2005,62)$ highlighted some of the challenges and problems facing managers such as: the stresses and pressures of a turbulent pace of life, contemporary life styles underscore the lack of community and connection, people look for something meaningful in their lives, something beyond the job, others desire to integrate their life values with professional values. Marques (2006) described the present organizational workplace environment as "The prevailing stressful atmosphere seems to be more a rule than an exception in Corporate America". More than that, Marques said "The average organizational environment, by definition, leans toward toxic rather than toward healthy. A very significant issue that is associated with job stress is job burnout. According to Schacher (2007). "Professional burnout has long been a problem for organizations, yet it wasn't until recent decades that the condition has been given serious recognition". Similarly, Robbins and Coulter $(2005,304)$ proclaim that "Workplace surveys still show high levels of employee stress stemming from work-life conflicts".

An issue of most importance to managers and to those people they serve, at home and abroad - is managerial ethics and social responsibility. Corruption, bribery, manipulation and misrepresentation of financial information, intimidation, and other unethical conducts and behavior are widely practiced on worldwide basis. The result was catastrophic and disastrous economic, social and financial consequences. Inside organizations human rights are not enforced. There is a great and urgent need to institutionalize and enforce high ethical standards to help solve ethical dilemmas and ensure that organizational members behave ethically. Also, ethical standards will encourage and help in institutionalizing active corporate social responsibility practices and actions. The pressures on organizations to pursue active socially responsible policies and practices are steadily increasing. Organizations are demanded to make a constant significant contribution to social advancement and development.

Also, organizations need to emphasize sustainable growth and development and fully recognize limited resources. Moreover there are more and more voices calling of "greening" of organization and management. Organizations should be fully aware of the impact of their operations and decisions on the global environment. Managers are under growing pressers to address serious global environment problems such as: global warming, pollution (air, water, and see), natural resource depletion, industrial wastes and toxic accidents, etc.

One of the greatest challenges facing leaders today is "The need to develop business models that accentuate ethical leadership, employee well-being, sustainability and social responsibility without sacrificing profitability, revenue growth and other indicators of financial performance. Top managers need to simultaneously maximize the so-called triple bottom line, or "People, planet, profit" (Fry and Sloum, Jr., 2008).

Business research and management literature has been over flown with prior studies supporting so many significant positive results of QWL.QWL has been strongly associated with job satisfaction, and job satisfaction has been strongly associated with reduced turnover, reduced absenteeism, reduced lateness, reduced complaints, lower rate of complaints, lower rate of thefts, higher social citizenship (willingness to help other employees and customers, and being more cooperative (Cohen et al., 1997, Yolder, 1995; MacRobert et al., 1993; Luthans,1992: 115). Moreover, job satisfaction may affect quality service and organizational commitment (MacRobert et al., 1993; Joseph and Deshpande, 1997). Lau (2000), after conducting a study comparing QWL companies with non QWL companies, found that: QWL companies had higher sales growth, higher asset growth, higher ROI, and a higher profit margin than other non QWL companies. Lau added, QWL contributes to a company's ability to recruit and retain quality people, and also it enhances company's competitiveness. An important positive influence QWL has on employees is that it will positively nurture a more flexible, loyal and motivated work force, which is essential to attain company's competitiveness (Bassi and Vanburen, 1997).

Roth and Jackson (1995) empirically found statistically significant correlations between QWL and business performance (in terms of market share, stakeholders value, and business sustainability.Gyan-Baffour (1999), studied the effect of employee participation and work design and found that firms that had higher levels of employee participation and higher levels of flexible work design outperformed firms with lower levels of employee participation and work flexibility.

Commenting on the benefits of QWL, Morhead and Griffin (2000, p. 549) said:

The benefits gained from QWL programs differ substantially, but generally they are of three types. A more positive attitude toward the work and the organization, or increased job satisfaction is perhaps the most direct benefit. Another is increased productivity, although it is often difficult to measure and separate the effects of QWL programs from the effects of other general factors. A third benefit is increased effectiveness of the 
organization measured by its profitability, goal accomplishment, shareholders' wealth, or resource exchange. The third gain follows directly from the first two.

As for work spirituality, studies reported that companies that introduced opportunities for spiritual development outperformed those that don't, and that spirituality in organizations is positively related to creativity, employee satisfaction, team performance and organizational commitment (Robbins and Coulter, 2005: 63; Fawcett et al., 2008). Fawcett et al. (2008) reported that work spirituality is positively associated with productivity, service quality, and retention. Marques (2006), a prominent researcher in work spirituality pointed that "In spiritual work place people will increasingly engage in team performance, leading to greater output, and hence, be translated to increased job satisfaction".

QWL influence extends beyond an individual's work life to personal life and well - being. Employment role experiences exert direct effects on different aspects of personal well - being. Personal well - being influences parent - child and interposal interactions, which intern affect child behavior and marital functioning respectively (Barling, 1995).

Commenting on the importance of QWL, Marques (2006) reported that "Individuals who are satisfied with their work environment, will generally be less stressed outside of work place. Overall, these persons will have greater sense of well - being, and an enhanced desire to make others (at work and outside) share in their contentment". Luthans (1992) reported that high job satisfaction was associated with good physical and psychological health. Scott (1992: 320-23) pointed that "employees who are experiencing alienation and coercion at work, will carry this attitude to personal life, and will refrain from engaging in community political and social activities".

\section{Explanation of QWL and Human Well-being}

\subsection{What Is $Q W L$}

The term/ phrase quality of work life (QWL) was first introduced in the $1960 \mathrm{~s}$ (Davis, 1977). The original use of QWL referred to the quality of the relationship between the worker and the working environment considered as a whole, and was intended to emphasize the human dimension of work frequently forgotten in the concentration on the technical and economic factors of job design (Gray and Smeltzer, 1989: 641). Robbins (1989: 207) defined QWL as "a process by which an organization responds to employees' needs by developing mechanism to allow them to share fully in making the decisions that design their lives at work. Another definition suggested by Lau (2000), QWL is" the favorable conditions and environments of a work place that support and promote employees' satisfaction by providing them with rewards, job security and growth opportunities". Schermerhorn et al. (1994:51) commented on QWL as follows:

The term has gained deserved prominence in OB (Organizational Behavior) as an indicator of the overall quality of human experience in the workplace. It is a concept that expresses a special way of thinking about people, their work and the organizations in which their careers are fulfilled. QWL establishes a clear objective that high productivity should be achieved along with job satisfaction by the people who do the required work.

While quality of life has been intensively searched and studied, there is relatively little literature on QWL; only recently the subject has attracted more scientists, and researchers. Writers don't agree on what are its main facets or constituents. The literature reveals that different models of QWL have been proposed by various authors and writers; following is a brief discussion of a number these models.

Nadler and Lawler III, (1983) stressed that true commitments to QWL are highlighted by the following benchmarks of managerial excellence:

1) Participation - involving people from all levels in decision making.

2) Trust - redesigning jobs, systems and structures to give people freedom at work.

3) Reinforcement - creating reward systems that are fair, relevant and contingent on work performance.

4) Responsiveness - making the work setting more pleasant and able to serve individual needs.

Gray and Smeltzer (1989: 642- 643) identified the following eight factors for QWL:

1) Adequacy in compensation.

2) Safe and healthy working conditions.

3) Immediate opportunity to use and develop human capacities.

4) Opportunity for continued growth and security.

5) Social integration in the work organization.

6) Constitutionalism.

7) Balance of work and life.

8) Social relevance of work life. 
Blegan (1993) conducted a meta - analysis concerning work satisfaction of nurses, and Knox and Irving (1997) conducted a meta - analysis concerning nurses and QWL. QWL factors resulting from these two meta - analysis include:

Reduced work stress, organizational commitment and belonging, positive communication, autonomy, recognition, predictability of work activities, fairness, clear locus of control, organizational decisions, low role conflict, job performance feedback, opportunities for advancement, and equitable pay levels.

Schermerhorn et al. (1994: 56- 57) suggested that QWL is one that offers the following: fair pay, safe working conditions, opportunities to learn and use new skills, room to grow and progress in career, protection of individual rights, and pride in the work and in the organization.

Levering and Moskowitz (1999) rated the best 100 companies to work for in the U.S. on the basis of the following six different criteria:

1) Pay and benefits.

2) Opportunities for growth.

3) Job security.

4) Pride in work and autonomy.

5) Openness and fairness.

6) Camaraderie and friendliness.

Lewis et al. (2001) suggested that QWL comprises the following general topics:

1) $\mathrm{Co}$ - worker and supervisor support.

2) Teamwork and communication.

3) Job demands and decision authority.

4) Patient/ resident care.

5) Characteristics of the organization (policies, procedures, leadership style, operations.. etc).

6) Compensation and benefits.

7) Staff training and development.

8) Overall impression of the organization.

Edvardsson and Gustavsson (2003) recommended the following six work environments as a prerequisite for success in new service development:

1) Opportunity to exercise control over one's own work situation.

2) Opportunity to develop security and meaning.

3) Opportunity to develop social relations at and through work.

4) Opportunity to keep a social distance (disengagement) to the job.

5) Opportunity to maintain good health and avoid stress.

6) Opportunity to work in safe physical environment.

Examining the above - mentioned, and other, QWL models, one can notice the following:

1) Writers and researchers generally agree on the importance of QWL to individual and organizational performance and success. However, there is no such unanimous agreement on QWL factors or dimensions.

2) Most of QWL models, discussed above and others, view QWL as a complex multi - facet, multi dimensional construct. It encompasses a wide range of dimensions/ constituents including structural, social, cultural, etc.

3) The dimensions/ facets of QWL, whatever they are, are interdependent and interacting, and the result of this is much greater than the sum of the individual factors/ dimensions. Therefore, understanding of the QWL requires thorough consideration of the bigger picture - the total workplace context.

4) In a broader sense, QWL can be referred to as the whole goodness and well - being of individual employee that is the result of total work place context - at work place environment - physical, structural, cultural, social, etc.

5) All models view that QWL and general QL are interdependent and interwoven and that QWL plays a significant role in QL in general, and that QWL in organizations is a major component of quality of life in general (physical, material, psychological, spiritual, etc.). Thus high value and emphasis has been placed on high QWL and its association with the total human well - being.

An important phenomenon that has gained momentum and closely related to QWL is "workplace spirituality" deserves a brief discussion. 
"Workplace spirituality" or "spiritual organization" has recently attracted the attention and interest of a steadily increasing number of scientists and researchers from different disciplines, including organization and management field. The literature is rich with theoretical research on the topic, yet there is no agreed upon definition of the concept or phenomenon. This is not surprising, because the nature of the topic is very intensely and strongly personal. However its influence on an employee's professional and personal lives and on organizational performance is widely strongly confirmed.

Ashmos and Duchon (2000) defined work place spirituality as "the recognition that people have an inner life that nourishes and is nourished by meaningful work that takes place in the context of community". Milliman et al. (2003) state that an organization is spiritual in the extent it serves as an outlet for its members to satisfy inner needs, to have a positive impact on society, to develop strong connections to others, and to have consistency between one's core beliefs and the values of the organization.

Elaborating on organizational spirituality, Marques (2006) stated:

"Spirituality is a higher awareness that entails realization of being interconnected to all other living beings, showing respect to everyone and everything that lives... and realizing that there is more to life than our physical state of existing or that which is visible to us. It is therefore essential that the experience of performing our duties should be one that is providing to all involved. Hence, providing ourselves and those we deal with in the workplace with feelings of trust, belonging, meaning, and fulfillment in all areas that we consider important to the quality of our lives".

It is not surprising that no agreed upon definition of work spirituality exists, because of the very intensely and strongly personal nature of the subject. However, most definitions and perspectives of the topic focus on three common themes/ aspects: meaningful work, community (inter connectedness) and positive organizational/ mission.

\subsection{Human "Well - being"/ "Wellness"}

Human "well - being", "wellness", "quality of life", "goodness" have recently gained a steadily increasing attention by scientists and researchers from different fields. Attempts have been made to "articulate a vision of the "good life", "well - being", "wellness" and "identify what contributes to such "good life", "well - being" or "wellness". Traditional models focus on life tasks. Most of these models identity the following life task components: physical intellectual, social, spiritual, emotional and occupational domains (Eberst, 1984: Hawks, 1994: Sweeney and Witmer, 1991, Moyers et al., 2000).

In brief, each life task includes the following:

- Physical health includes exercise, nutrition, and rest.

- Intellectual health is the ability to reason, analyze, be creative, and make rational decisions.

- Social health is the ability to create and maintain loving, genuine relationships.

- Spiritual health has varied meanings in the models, but typically includes the concept of spirit as the Life-giving force.

- Emotional health is the ability to identify, manage, and express emotions in an appropriate way and includes the ability to cope with distressful situations and to adjust to change.

- Occupational or career health includes doing work that is meaningful and fulfilling (Purdy and Dupey, 2005).

Another model is the "Wheel of Wellness" developed by Sweeney and Witmer (1991), and updated later by Sweeney et al. (2000). According to this model, Wellness is a way of life geared to optimal health in which the mind, body, and spirit are integrated and an individual can live fully. Five life tasks are integrated by the model, these are: Spirituality, self-direction, work and leisure, friendship and love, with spirituality as the prominent one (Sweeney and Witmer, 1991; Myers et al., 2000).

Later, in 2003, Myers and Sweeney developed the Indivisible Self: An Evidence-Based Model of the Wellness. Here, indivisibility of self is placed at the center, with five second-order factors clustered around the center. These second-order factors are: coping, creative, social, essential and physical (Myers and Sweeney, 2003).

The model of well-being proposed in this paper builds on and extends the first one. It integrates the following components or dimensions: physical, intellectual, social, emotional, spiritual, psychological, and ethical self/will-being.

\section{QWL - Human Well - being Linkage: Proposed Framework}

QWL and general human well-being are very interdependent and interwoven. QWL has great impact on general well-being and on each state / self (physiological, psychological, etc,) Each of QWL and human well-being is a multi-faceted and multi dimensional complex construct that encompasses many interacting factors. Thus every QWL dimension/factor may affect more than one state/self of human well-being. An example, job stress and burnout can badly affect physiological, psychological, emotional, intellectual and even spiritual well-being 
(Robbins and Coulter, 2005; Schacher, 2007). Not to mention, the serious social consequences and it costs national economy very much. Now, there are many organizational measures that can reduce job stresses and burnout, including: organizational structure, job design, supervision, group support, physical environment, etc.

Another example is spiritual health, the most common themes of spirituality are: meaning, purpose, being connected to others, contributing to broader society and world betterment, fulfilling one's potential, alignment of personal and professional Values (Ashmos and Duchon,2000, Duchon and Plowman, 2005; Kinjerski and Skrypenk 2006). Each of these themes can be affected by certain QWL factors. A feeling of belonging (community) can be created and maintained through job design, organizational structure, organizational culture and organizational mission.

It clearly appears that the linkages between QWL and human well-being are very much complicated and multifaceted, and can't be examined by one single research. Figure (1) presents the main QWL factors and the main states of human well-being, and the outcomes resulting from QWL- well-being linkage. Figure (2) presents the different QWL factors which affect each of human well-being, supported by a brief discussion.

$$
\begin{aligned}
& \text { "Insert figure (1) here" } \\
& \text { "Insert figure (2) here" }
\end{aligned}
$$

\subsection{Physical/ Physiological well - being}

There are many factors of QWL that can contribute to healthy physical/ physiological well - being of man; among these factors are:

- Salary and perquisites should be sufficient to maintain a socially acceptable standard of living (housing, clothing, food, medication, etc.), for the employees, and their families/ dependents.

- Pay, allowances, increments, rewards and promotions must be linked to performance.

- Income from job is steady (job security).

- Equitable rewards system.

- Reasonable workload and hours.

- Flexible work schedule, flexible working hours.

- Safe, wholesome and comfortable surrounding favorable to health.

- Work stresses are reasonable.

- Minimum risk of illness or injury, and health hazards.

- Reasonable paid leave.

- On - site exercise facilities, gym, sports area, and education for health, fitness, nutrition, healthier lifestyle, regular medical exam.

- $\quad$ Free/ subsidized medication and health care for employees and their dependents.

\subsection{Psychological well - being}

The psychological state of an individual employee will certainly have a significant influence on his/ her professional and personal lives. Psychological well - being requires job satisfaction, free from stress, tension, anxiety, boredom, frustration, loneliness, and alienation. The individual needs to have meaningful, purposeful work feeling invaluable individual, self - esteem, pride and competent; experiencing responsibility, self managing and exercising choice and influence. The organization can enhance and promote the psychological well - being of individual through many ways, including, but not limited to, the following:

1) Job design based on the Job Characteristics Model (JCM): task significance, skills variety, autonomy, task identity and feedback - can provide the following three psychological states: experienced meaningfulness, experienced responsibility, and knowledge of results (Garg and Rastogi, 2006).

2) Employee's empowerment and participation: allowing each employee to exercise self - determination and choice, having more influence on getting work done, having meaningful work and feeling pride and an invaluable member.

3) Organizational structure: organic, with low formalism, high decentralization, low (general) specialization: open and free communication across the organization, and using increasingly team - based structure.

4) Comfortable, safe, healthy, secure, pleasant/ work place, with minimum health risks and dangers and reasonable stresses.

5) Reasonable work load and work schedule which allow more leisure time so that employees can engage in family, recreational, sports, picnics, socializing activities.

6) Encourage and reward employees and provide paid leaves to engage in various community and social activities and issues.

7) Provide work place privacy that protects employees' humanity and dignity, and not intimidating them. 
8) Organizational commitment to establish and maintain justice (both distributive and procedural) across the entire organization.

9) Advocating and pursuing constantly active corporate social responsibility, which make the employee recognize the social relevance of his/ her work and feel that what he/ she is doing is congruent with personal values, beliefs, etc.

10) Leadership that pays attention to the concerns and developmental needs of each individual, and provides individualized consideration and intellectual stimulation; excites, arouses and inspires followers (Robbins and Coulter, 2005: 433).

\subsection{Emotional Well - being}

Workplace is full of emotions and passions, such as pleasure, respect, self - esteem, security, pride, safety, courage, self - confidence, love, hate, joy, comfort, grief, optimism, pessimism, affection, friendship, empathy, etc. The importance and influence of "emotions" and "emotional intelligence" has been recently frequently cited in literature. Emotions and emotional processes play an important role in decision making and in enhancing service provision, profitability, political learning, increase work motivation, enhance customer service and work performance (Gabriel and Griffins, 2002; Brotheridge and Lee, 2008).

Organizations can, and should, create a workplace context that can enhance developing, nurturing and maintaining good emotional well - balanced, stable and positive affective self, enriched with emotions and passions such as: warmth, love, kindness, pride, self- esteem, sympathizing with others, friendliness, caring, outreaching, openness, cooperation, optimism, delight and empathy. The measures that organizations need to undertake include, but not limited to, the following:

- Supervisor and group members empathize with each member and provide very amicable, friendly, family like and supportive environment. The individual needs to feel he/ she is accepted, welcomed, trusted, respected and receives all assistance, encouragement and support he/ she needs (at the personal/ family levels).

- Shared vision, common goals create a sense of belongingness and community.

- Redesign of jobs to provide frequent face - to - face communication, social contacts with customers, closeness to people, feeling of affinity, liking or attraction.

- Moving organizational design towards more team - based structures, which reinforce face - to - face contacts and interaction.

- Work requirements should not take up leisure and family time on a regular basis.

- Effective, friendly, supportive and appreciative leadership.

- Organization culture that stresses caring, helping, openness, and sensitivity to others.

- Provide family-like work environment: on - site child care, summer day camps, flextime, flexplace, job rotation, job sharing, company sponsored family picnics and recreational, social activities/ events, and sports facilities.

- Allow employees time to make a home not merely a house, and for other things personal such as sports, recreation, visiting, socializing, friendship, hobbies, interests, etc.

- Train people to understand their emotions, their sources and how to manage their emotions and those of their employees.

\subsection{Intellectual/ Mental Well - being}

Promoting and enhancing responsible citizenship behavior at organizational, community, national and global levels, requires organizations to continuously upgrade and develop the intellectual/ mental state of an individual far beyond job - related education and learning. Training and learning should extend to whatever skills, capabilities, knowledge and attitudes that serve personal, organization, community, national and global goodness and welfare. Organizations can undertake the following measures and actions:

- Provide good opportunities for learning, training and development.

- Employee's empowerment and participation.

- Job rotation, job enrichment, job integration.

- Develop a culture that encourages and rewards learning and self development, knowledge sharing, etc.

- Use team-based and cross-functional, cross- hierarchical structures.

- Management and organizational culture should give high value to knowledge and learning.

- Provide employees with regular feedback on results of work.

- Provide enough opportunities, facilities, support, and paid leaves to encourage and reward employees, to attend seminars, workshops, conferences run by other institutions, and engage in research projects relevant to work, organizational and/ or broader societal needs at the national and even global levels. 


\subsection{Social Well - being}

Workplace environment should encourage, support and even reward employees to develop and maintain loving, genuine, caring relationships with co - workers and all with whom employees deal and interact inside and outside workplace, so that an employee feels being accepted and belonging to larger social groups.

Following is a number of means and ways by which an organization can enhance the social well - being of its employees.

- Design jobs according to Job Characteristics Model (JMD) which allows employees to engage in wider contacts with customers, clients, suppliers, etc.

- Team - based structure: using widely teams and team - based structures and designs, to provide greater opportunities for employees to interact and develop close social networks.

- Organic, structure that provides and encourages smooth flow of communication throughout the organization.

- Develop and maintain an organizational culture with such characteristics as: mutual understanding, respect, enhance and encourage building healthy social networks.

- Reasonable workload and work schedule and hours which allow leisure time for employees to engage in various community and national activities.

- Sponsoring various social, recreational, cultural and other activities, including employees' families, on site and outside organization premises.

- Strengthen links and contacts with relevant organizations at the national level and abroad.

- Strengthen partnership, collaboration, and joint ventures with other organizations, at home and abroad.

4.6 Ethical/ Moral Well - being

One of the important and critical challenging issues facing organizations and managers at present, and in future, is ethical/ moral crisis. Recently, unethical conducts and behaviors by organizational members, especially managers, have been steadily growing in various organizations in most parts of the world. Lying, misrepresentations, financial and accounting manipulations, greed, collusion, bribes, gifts, unfairness, nepotism, favoritism, undermining fundamental rights of people, etc. have been widely reported and publicized in many parts of the globe. Those and other ethical abuses have often resulted in very devastating economic, social, psychological and emotional consequences for individuals, organizations and societies.

It is very obvious that there is an increasingly very pressing need to "upgrade" ethical standards and highly ethical behaviors at, and outside, the workplace setting. Among the measures and actions that organizations can, and should, undertake to address this issue and bring a reversal trend, include, but not limited to, the following:

- Organizations should clearly recognize and actively pursue serving the interests and welfare of broader societies, at community, national and global levels, as their ultimate mission and purpose, rather than serving only the interests of owners and managers.

- Institutionalize, nourish and enforce a strong ethical culture that stresses and respects: integrity, honesty, openness, truthfulness, accountability, transparency, equity, risk tolerance, focuses on means as well as ends, collaboration, and respects and protects fundamental rights.

- Set, communicate and firmly implement a code of ethics which states clearly which behaviors, are good, right, wrong and bad.

- Train and educate all organizational members on ethics.

- Institutionalize and firmly implement whatever policies, procedures, committees and mechanisms necessary to implement effectively the code of ethics.

- Encourage and reward behaviors that contribute to greening organization and management, preserving and protecting environment and natural resources and safeguards our planet, and enhancing global citizenship behavior.

- Managers should present a visible role model, communicate ethical expectations, provide ethical training, visibly reward ethical acts and punish unethical ones, and provide protective mechanisms so employees can discuss ethical dilemmas and report unethical behavior without fear (Robbins and Coulter, 2005:60).

- Respecting core or universal values: respect for human dignity, respect for basic rights, and be good citizens (Robbins and Coulter, 2005:199).

4.7 Spiritual well - being

Concepts of "Spiritual wellness" or "health" or "well - being" now permeate the literature, especially in psychology, and recently in organization and management field. There is no agreed on definition in literature, this is not surprising since the topic is very strongly and intensely personal in nature. 
Several models of spiritual wellness identify spirit as the central energy source that allows an individual to engage in the activities that are associated with the other components of life (Purdy and Dupey, 2005). Purdy and Dupey (2005) affirmed that spirituality is the central force that determines an individual's health and satisfaction within each dimension (Physical, social, emotional, intellectual, occupational). Their Holistic Flow Model of Spiritual Wellness includes: a belief in an organizing force in universe, connectedness, faith, movement toward compassion, the ability to make meaning of life, and the ability to make meaning of death (Purdy and Dupey, 2005). Barrett (1999) pointed that spiritual needs are met when our work aligns with our passion and has meaning for us, or we feel we are able to make a difference through our ideas or being of service to others. Covey $(1989,292)$ proclaimed that "the spiritual dimension is your core, your center, your commitment to make a difference".

Spiritual influence in the workplace has gained momentum in recent years and is often described in terms of organizational spirituality (Fawcett et al., 2008). Building and maintaining "spiritual workplace" or spiritual organization is never an easy task. It requires drastic steady changes in the various organizational realms including structure, culture, leadership, job design, rewards system, training etc.

Building a spiritual organization requires developing and maintaining an organizational culture with the following characteristics:

1) Strong sense of purpose (meaningful purpose).

2) Focus on individual development.

3) Trust and openness (among members of the organization and between members and customers, suppliers, etc.).

4) Employee empowerment.

5) Toleration of employee expression: allow people to be themselves - to express their moods and emotions (Burack, 1999; Wagner - Marsh and Conley, 1999; Cash and Gray, 2000).

Fawcett et al (2008) pointed that building a spiritual organization requires a people - centered, inspiring organizational culture which is built on the following three main factors:

1) Core values: community, accomplishment, self - esteem, and balance.

2) Organization climate: affirmation, belonging, competence.

3) Work place attributes: job design, empowerment, respect, equality, collegiality, etc.

Marques (2006) pointed that many writers stressed that the implementation of a spiritual mindset in the work place as being a leadership responsibility. Gilber Tan recommended the following interventions to promote spirituality:

- Organizational culture.

- Redesign organizational structure to support spirituality at work (meaningful job).

- Train people to raise awareness and competencies in integrating spirituality and work, training people on the spiritual basis to life and business.

- Align reward and appraisal systems to recognize employees for acting ethically and promoting a sense of community in the organization (Rahim, 2007:220 -21).

The role of leaders in building and maintaining organizational spirituality has been affirmed by more than one writer. In recent years, having a spiritual guide has become increasingly popular (Konz and Ryan, 1999). They proclaimed that the spirituality of leaders is the key to maintaining the organization's spirituality. The leaders' spirituality should guide what they do, so through their actions, they bring their spirituality to life. The key to maintaining an organizational culture is the philosophy and values of the organization's leaders. Leaders' spirituality also influences the selection and socialization of employees, and through mission statement. Fry (2004) adds that spiritual leadership can predict ethical well - being, positive human health and corporate social responsibility.

An important dimension associated with spiritual leadership is empowerment. Giacalone et al., proclaimed “.... Especially important for work place spirituality is empowerment". Neck and milkman (1994) argued that a critical factor in whether spiritual - based management practices result in improved performance involves empowering employees with the capability to participate in redeveloping and implementing the organizational vision. The reason for this is that all people seek to reach their full potential and empowering employees is the only way individuals can attain their fullest sense of growth and contribution.

\section{Conclusion and Future Research}

More value has been placed recently on a high QWL for many reasons. It enhances and promotes the total human well-being of organizational members, upgrades their professional roles and other personal roles at family, community, national and global levels. High QWL can result in better organizational performance, effectiveness, innovativeness, etc. Consequently, contributing to better life for all those peoples whom 
organizational members serve, and with whom they deal and interact. High QWL can help protect and preserve our lives and the earth planet and what lives on it. Not to mention that it is believed that people deserve high QWL; that a satisfying work life is good in and of itself. Thus developing and maintaining high QWL place work deserves greatest attention and concern, though it is no easy task.

The proposed framework presented in this paper has been developed to reflect the complexity of both QWL and human well-being to broaden managers' understanding and their recognition of the importance of the relationship between QWL and human well-being. Also, the conceptual framework would help managers focus attention and effort on building and nurturing those workplace factors that can contribute more significantly to high QWL. However managers need to be aware that some workplaces are more or less susceptible and adoptive to such transformation.

Hopefully, the proposed framework would stimulate further research, especially empirical research aimed at testing the model in real life setting. The framework provides a promise for researchers to study the relationship between certain QWL factors and particular human well-being states, in different settings. It is expected that further research would examine which QWL factors can enhance a particular well-being self/state in different settings.

\section{Acknowledgement}

The authors are grateful to the Applied Science Private University, Amman, Jordan, for the financial support granted to cover publication fee of this research article.

\section{References}

Ashmos and Duchon. (2000). Spirituality at work: conceptualization and measure. Journal of Management Inquiry, 9 (2), 134 - 145. doi:10.1177/105649260092008, http://dx.doi.org/10.1177/105649260092008

Barling, Julian. (1995). Work and family: in search of the missing links. Employee Counseling Today, 7 (7), 18 37.

Barrett, R. (1999). Why the future belongs to value added companies. The Journal for Quality and Participation, 97 (2), 117- 131.

Bassi, L.J., and Vanburen, M. Z. (1997). Sustaining high performance in bad times. Training and Development, $51(6), 31-42$.

Blegan, M. (1993). Nurses' job satisfaction: a Meta - analysis of related variables. Nurse Research, Vol. 42, 36 41.

Brotheridge, Cleste and Lee, Raymond (2008). The emotions of managing: an introduction to the special issue. Journal of Managerial Psychology, 32(2), 108 - 17. doi:10.1108/02683940810850763, http://dx.doi.org/10.1108/02683940810850763

Burack, E.H. (1999). Spirituality in the workplace. Journal of Organizational Change Management, 12 (3), 280 - 291, doi:10.1108/09534819910282126, http://dx.doi.org/10.1108/09534819910282126.

Cash, K.C., and Gray, G.R. (2000). A framework for accommodating religion and spirituality in the workplace. Academy of Management Executive, August, 124 - 133.

Cohen, S.G., Chang, L., and Ledford, G.E. (1997). A hierarchical construct of self- management and perceived work group effectiveness. Personnel Psychology, 50 (2), 275 - 308, doi:10.1111/j.1744-6570.1997.tb00909.x, http://dx.doi.org/10.1111/j.1744-6570.1997.tb00909.x

Covey, S. (1989). The seven Habits of Highly Effective People. New York, Simon and Schuster.

Davis, L. (1977). Enhancing the quality of work life: developments in the United States of America. International Labor Review, 116(1), 53-65.

Eberst, R. (1984). Defining health: a multidimensional model, Journal of Social Health, 54, 99-104. doi:10.1111/j.1746-1561.1984.tb08780.xPMid:6562286, http://dx.doi.org/10.1111/j.1746-1561.1984.tb08780.x PMid:6562286

Edvardsson, B., and Gustavsson, B. (2003). Quality in the work environment: a prerequisite for success in new service development, Managing Service Quality, 13 (2), 148 - 163, doi:10.1108/09604520310466851, http://dx.doi.org/10.1108/09604520310466851

Epps, Job. (1995). Respiring organizations: the skeptic's version. The Journal for Quality and Participation, 18 (4), $40-47$.

Fawcett S., Brau, J., Rhods, G., Witlark, G., and Fawcett, A. (2008). Spirituality and organizational culture: cultivating the ABC's of an inspiring work place. International Journal of Public Administration, Vol. 31, 420 438. doi:10.1080/01900690701590819, http://dx.doi.org/10.1080/01900690701590819

Fry, L., and Slowm, Jr. John. (2008). Maximizing the triple bottom line though spiritual leadership. Organization Dynamics, 37 (1), 86-96. 
Fry, L.W. (2003). Toward a theory of spiritual leadership. The Leadership Quarterly, Vol. 14, 693 - 727 , doi:10.1016/j.leaqua.2003.09.001, http://dx.doi.org/10.1016/j.leaqua.2003.09.001

Gabriel, Yianic and Griffins, D.S. (2003). Emotions, learning and organization. The Learning Organization, 9 (5), $214-221$.

Gary, P., and Rastogi, R. (2006). New model of job design: motivating employees performance. Journal of Management Development, 25 (6), 572 - 587, doi:10.1108/02621710610670137, http://dx.doi.org/10.1108/02621710610670137

Giacalone, R. et al. From Advocacy to Science: The Next Steps in Work place Spirituality Research. [Online] Available: http:// www.tar/eton.edu fry/ SLT Paloutzian Final. rtf.

Gray, E.R., and Smeltzer, L.R. (1989). Management: the Competitive Edge, New York, Macmillan Publishing Co.

Gunther, M. (2001). God and Business. Fortune, (July), p. 58 - 70.

Gyan - Baffour, George. (1999). The effects of employee participation and work design on firm performance: a managerial perspective. Management Research News, 22 (6), 1-12.

Hawks, S. (1994), Spiritual health: definition and theory. Wellness Perspective, 10(4), 3-14.

Hian, C., and Einstein, W. (1990). Quality of work life (QWL): what unions can do? S.A.M. Advanced Management Journal, 55 (2), 17 - 22.

Joseph; J. and Deshpande, S.P. (1997). The impact of ethical climate on job satisfaction of nurses. Health Care Management Review, 22 (1), 76 - 81.

Kinjerski, Val and Skrypnek, Berna (2006). Measuring the Intangible: development of the Spirit at work scale. Paper presented at the sixty-fifth Annual meeting of the Academy of management, Atlanta, GA.

Knox, S., and Irving, J.A. (1997). An interactive quality of work life model applied to organizational transition. Journal of Nursing Administration, 27 (1), 39 - 47. doi:10.1097/00005110-199701000-00009PMid:9006600, http://dx.doi.org/10.1097/00005110-199701000-00009PMid:9006600

Konz, G.N., and Ryan, J.C. (1999). Maintaining an organizational spirituality: no easy task. Journal of Organizational Change Management, 12 (3), $200-210$, doi:10.1108/09534819910273865, http://dx.doi.org/10.1108/09534819910273865

Lau, R.S. (2000). Quality of work life and performance: an adhoc investigation of key elements in the service model. International Journal of Service Industry Management, $11 \quad(5), \quad 422 \quad-\quad 437$. doi:10.1108/09564230010360164, http://dx.doi.org/10.1108/09564230010360164

Levering R., and Moskowitz. (1999). The 100 best companies to work for in America. Fortune, January $11^{\text {th }}$, pp. $118-144$.

Lewis, D., Brazil, K., Kruger, P., Lohfeld, L., and Tjam, E. (2001). Extrinsic and intrinsic determinants of work life. Leadership in Health Services, 14 (2), ix - xv.

Luthans, F. (1992). Organizational Behavior, $6^{\text {th }}$ ed. New York McGraw-Hill Inc.

Marques, Joan F. (2006). The spiritual work: an examination of the ripple effect that enhances quality of life - in and outside the work environment. Journal of Management Development, 25 (9), 884 - 895. doi:10.1108/02621710610692089, http://dx.doi.org/10.1108/02621710610692089

McRbert, M., Schmele, J., and Honsen R. (1993). An analysis of job morale factors of community health nurses who report a low turnover. Journal of Nursing Administration, 23 (6), 22 - 27. doi:10.1097/00005110-199306000-00006, http://dx.doi.org/10.1097/00005110-199306000-00006

Milliman, J., Czaplewski, A.J., \& Ferguson, J. (2003). Workplace Spirituality and employee work attitude. Journal of Organizational Change Management, Vol. 16, 426 - 447, doi:10.1108/09534810310484172, http://dx.doi.org/10.1108/09534810310484172

Moorhead, G., and Griffin, R. (2000). Organizational Behavior: Managing People and Organizations. Delhi, A.I.T.B.S. Publishers and Distributors.

Myers, J. et al. (2000). The wheel of wellness counseling for wellness: A holistic model for treatment planning, Journal of Counseling and Development, 78, 251-266.

Myers, J., and Sweeney, T. (2003). The indivisible self: an evidence - based, emerging model of wellness, Paper presented at the annual conference of the American Counseling Association, Anaheim, CA.

Nadler, David and Lawler, Edward. (1983). quality of work life: perspectives and directions. Organizational Dynamics, Vol. $\quad 11, \quad 22 \quad-36, \quad$ doi:10.1016/0090-2616(83)90003-7, http://dx.doi.org/10.1016/0090-2616(83)90003-7

Neck, C.P., and Milliman, J.F. (1994). Thought self - leadership: finding spiritual fulfillment in organization life. Journal of Managerial Psychology, 9 (6), 9 - 16, doi:10.1108/02683949410070151, 
http://dx.doi.org/10.1108/02683949410070151

Purdy, M., and Dupey, P. (2005). Holistic flow model of spiritual wellness. Counseling and Values, Vol. 49, 95 - 106, http://dx.doi.org/+DOI

Rahim, M Afzalur. (2007). Current Topics in Management, Ed (2007). Vol. 12. New Jersey, Transaction and Publishers.

Robbins, S. (1989). Organizational Behavior: Concepts, Controversies and Applications. Englewood Cliffs, New Jersey, Prentice - Hall.

Robbins, S., and Coulter, M (2005). Management, $8^{\text {th }}$ ed., International edition, New Jersey, Pearson - Prentice Hall, Inc.

Roth, A., and Jackson, W. (1995). Strategic determinants of service quality and performance: evidence from the banking industry. Management Science, 41 (11), 1720-33, doi:10.1287/mnsc.41.11.1720, http://dx.doi.org/10.1287/mnsc.41.11.1720

Schacher, Casey. (2007). Job burnout as a library management Issue, Library Worklife, 4 (Special issue), 1-10. [Online] Available: http://www.ala-apa.org/newsletter/vol 4 no special/work life. html \# beat.

Schermerhorn, John, Hunt, James and Osborn, Richard. (1994). Managing Organizational Behavior, $5^{\text {th }}$ ed. New York, John Wiley and Sons.

Scott, Richard. (1992). Organizations: Rational, Natural and Systems, $2^{\text {nd }}$ ed. Englewood Cliffs, New Jersey, Prentice-Hall Inc.

Sweeney, T., and Witmer, J. (1991). Beyond social interest: striving toward optimum health and wellness. Individual Psychology, 47, 525-539.

Terez, T. (1999). Meaningful work. Executive Excellence, 16 (2), 19 - 20.

Wagner - Marsh, F., and Conley, J. (1999). The fourth wave: the spirituality - based firm. Journal of Organizational Change Management, 12 (3), 292 - 302.

Yolder, L. (1995). Staff nurses' career development relationship, and self - reports of professionalism, job satisfaction and intent of stay. Nursing Research, 44 (5), 290 - 297.

\section{Total Workplace Context}

- Org. mission vision and goals.

- Pay, Perquisites.

- Job design.

- Organization structure.

- Conditions (health, safety, security).

- Learning + development opportunities.

- Organization culture.

- Corporate Social Responsibility.

- Leadership and empowerment.

- Manager and group support.

- Org policies, procedures, workplace spirituality.
Whole human "well - being"

- Physical/ Physiological.

- Psychological.

- Intellectual/ Mental.

- Spiritual/ Philosophical.

- Ethical.

- Emotional.

- Social.

\section{Outcomes}

- Higher organizational Performance.

- Enhanced creativity, innovation, commitment, etc.

- Meeting organizational stakeholders' expectations.

- Contributing to better lives for peoples at family, community and national levels.

- Upgrading human wellness at the global level.

- Safeguarding and preserving our earth planet and what lives on it.

Figure 1. QWL - Human “well - being” Relationship 


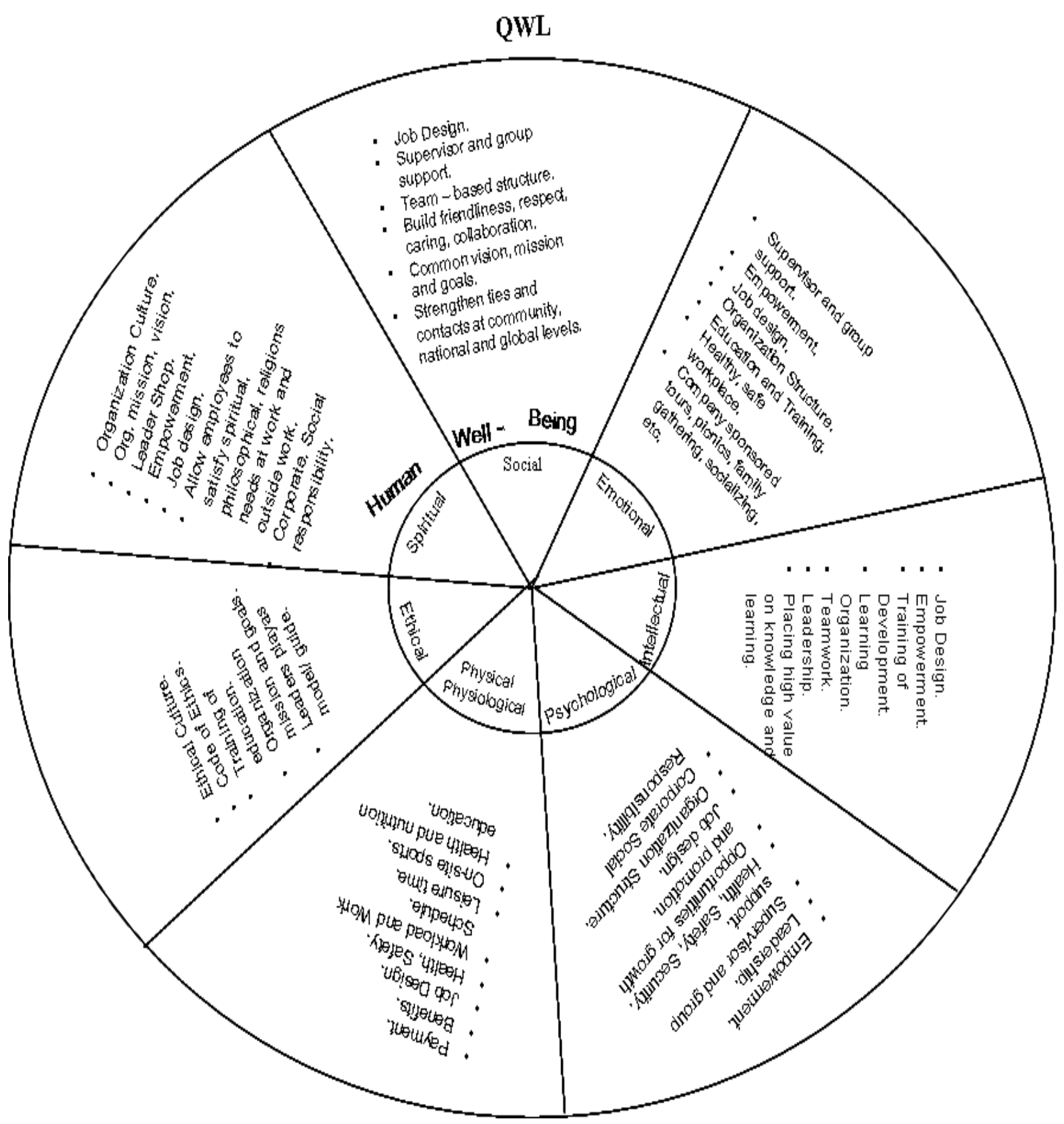

Figure 2. QWL-Human well-being Relationship 